\title{
Research as a Student: Is It Worth a Try? An Insightful Experience from a Middle Eastern Student
}

Muneer Al-Husseini. ${ }^{1}$

\section{The Experience}

About the Author: Muneer Al-Husseiniis fourth year medical student in Ain Shams University and a Regional Ambassador of the IJMS.

Submission: Jan 27, 2014 Acceptance: May 16, 2014 biological samples.
I was standing in a long queue at Cairo International Airport, waiting for my flight, with a box on my back containing a poster; only at that time I realized I was not dreaming anymore. It was real and, a few hours later, I would arrive in Porto City, Portugal to attend the 8th Young European Scientists (YES) meeting. In that meeting, I was going to present my first research experience; it would also be my first time representing the International Journal of Medical Students (IJMS), a partner of the meeting and for whom I work for as an Ambassador.

It all started when I was attending an ordinary anatomy lecture during my 2nd year. A professor at my class announced training positions for students who are interested in conducting research as undergraduates and who wanted to dive deep into this amazing world. I asked the professor for a position. He then asked me to make a team to start. I established a team consisting of students in my class. We were learning our first steps in conducting research.

At that time it was a little bit strange for undergraduates to be working in research and many other students and even professors were asking us why would we waste our time in research instead of studying. We kept working, however, and we spent more than six months with many hours each day learning and gaining new skills in the lab, animal house (where we performed experiments on animals), and with the technical issues regarding the preparation of biological samples. This latter technique was necessary for microscopic studies using an ordinary light microscope, scanning electron microscope, and the energy dispersive X-ray spectroscopy (EDS) which is used by geologists to analyze the elemental composition of stones as well as by biologists to analyze the chemical composition of

\section{First Personal Independent Student Research Experiences}

My research was about the corneal ulcer. It is a devastating complication and one of the common causes of blindness in Egypt. The major causes of corneal ulcers are trachoma and alkaline chemical burns. Trachoma, caused by the bacterium
Chlamydia trachomatis, is highly endemic in Egypt, especially in rural areas.' I started the research project with my team in spite of the limited resources. After six months of hard work in addition to studying for my 3rd year, my group came up with a manuscript.

The team decided to present the research in an international medical student conference so I browsed the internet looking for a conference and got a long list of conferences. We chose to submit the abstract in the 8th YES meeting as it was the most professional and suitable for our research. Later on, the abstract was accepted as a poster presentation.

As a medical student from the Middle East, I used to think that scientific meetings were just about presenting research. I was, however, quite wrong. The YES meeting was more like spending three full days of learning new knowledge, enjoying time in a new culture, and making like-minded friends from all over the world. The scientific program included the plenary, poster presentation, and oral presentations. There were workshops for different skills related to clinical, academic, and even human resources. I had two presentations: the first one was my poster presentation and the second one was about the IJMS. The program also included social activities in which I enjoyed seeing the most beautiful sights of Porto, a city full of historical and touristic attractions.

The part I liked the most was meeting with the scientists where we had the chance to chat with professors and experts from around the world. The professors were so friendly with students, supporting, advising, and willing to exchange scientific, personal, and career experiences. I made a lot of friends from different countries and cultures. There were students from Portugal, Russia, Turkey, Serbia, amongst others. What gathered us together was that we all shared the same interests in medical research.

\section{Why Reserach?}

Evidence-based medicine (EBM) has become the most effective paradigm in making clinical decisions, according to the most updated guidelines. Teaching EBM in medical schools has

${ }^{1}$ Medical student, Ain Shams University, Egypt. 
increased dramatically worldwide.-3 However, most medical schools in developing countries have not included EBM training courses in the curriculum. ${ }^{4}$ That is why I would like to emphasize the importance of learning the practice of EBM and building a strong research background to help implement these practices in one's future career. ${ }^{5}$

Even if a medical student does have a busy schedule, the research practice should continue along at the same pace as one's medical study; the earlier students start this process, the more benefits they will get. For example, early involvement in research allows for the better understanding of published work and it also allows one to discover a passion for a specific specialty in medicine - possibly influencing one's future career. ${ }^{6}$ The idea may seem difficult and even impossible for many different reasons but as a personal experience, I really recommend taking the very beginning steps towards becoming involved in research. I also recommend traveling for learning; whether traveling for an exchange program, doing clinical electives, or attending conferences, it's worth investing some time and resources on one's education.?

In addition, conducting research in a place where it is not that empowered is not only beneficial on the scientific level but it is also beneficial as a journey of awareness for other students, supervisors and program directors, encouraging them to direct more effort towards research. This is especially important in developing countries who already face many obstacles that include little funding, the lack of human resources, and ill-defined research goals. By considering research as one of the fundamental priorities, it will certainly lead these countries toward achieving innovative solutions to provide better healthcare practices and productive research environments. ${ }^{8-11}$

Todays' medical students are the future physicians. From here on comes the important role of students in understanding the concepts of research and its contribution to the progress of medicine and the service of humanity. That is one of the reasons why the IJMS has been created to promote the understanding of the concepts of research to medical students through several strategies. These include providing a feedback system on how to improve manuscripts to potentially achieve publication, gaining the exceptional experience to develop skills on the critical evaluation of manuscripts under the guidance of expert editors, and also introducing the internal functioning and workings of a peer-reviewed journal. ${ }^{12}$

\section{Final Words for the Curious Minds}

So what are the final take-home messages? Be initiative and start your independent research journey early by forming a like-minded team under the supervision of an inspiring mentor. Be Patient, Persistent and Passionate (the magical 3 P's). Manage your time efficiently. Improve your English language skills. Work on your presentation skills. Love what you do, do what you love, and if you have a curious mind, seek Research!. ${ }^{13-14}$

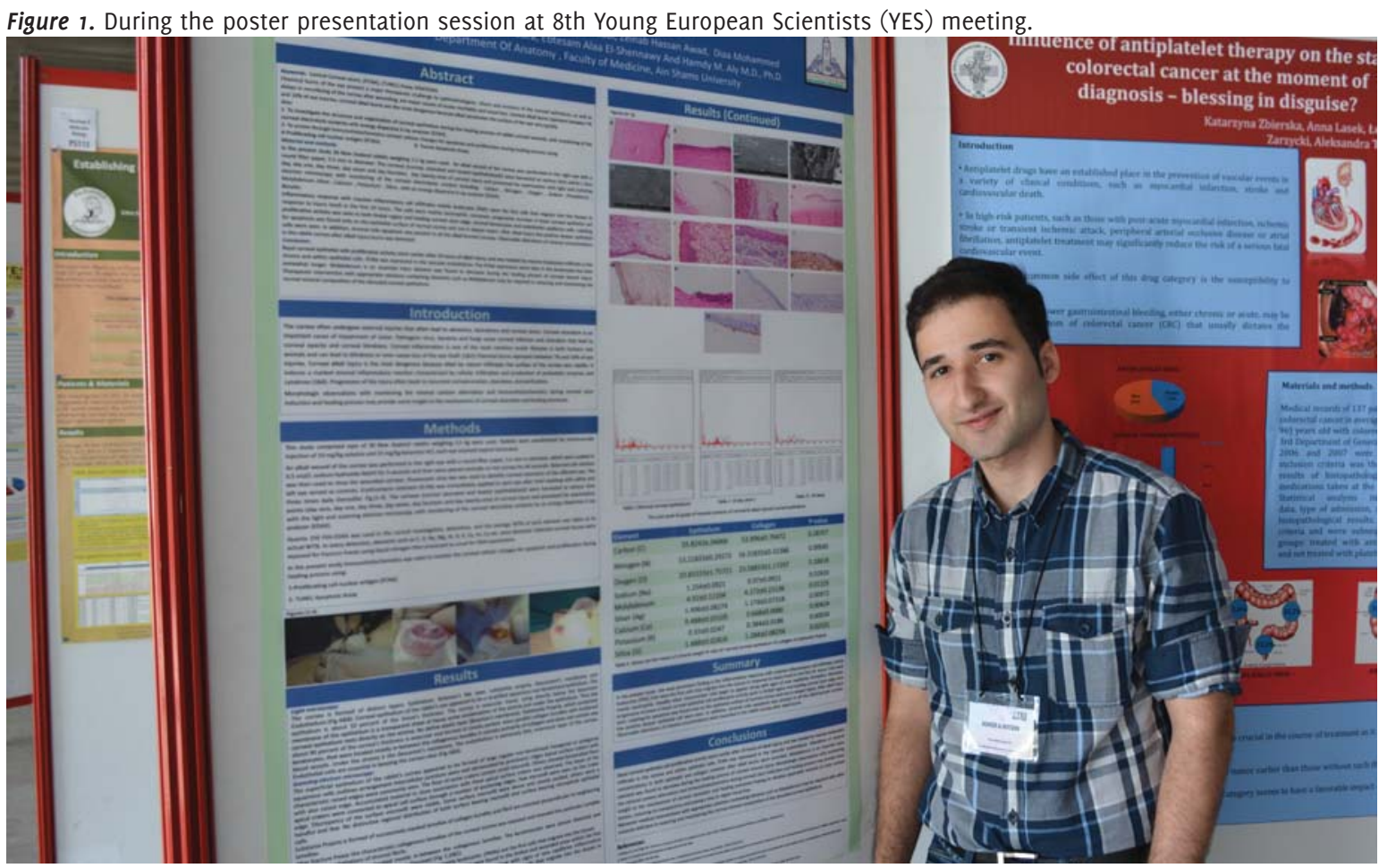




\section{Experience}

\section{References}

1. Ezz al Arab G, Tawfik N, El Gendy R, Anwar W, Courtright P. The burden of trachoma in the rural Nile Delta of Egypt: a survey of Menofiya governorate. Br J Ophthalmol. 2001 Dec;85(12):1406-10.

2. Lewis SJ, Orland BI. The importance and impact of evidence-based medicine. J Manag Care Pharm. 2004 Sep ;10(5 Suppl A):S3-5.

3. Dorsch JL, Perry GJ. Evidence-based medicine at the intersection of research interests between academic health sciences librarians and medical educators: a review of the literature. J Med Libr Assoc. 2012 Oct;100(4):251-7. 4. Liabsuetrakul T, Suntharasaj T, Tangtrakulwanich B, Uakritdathikarn T, Pornsawat P. Longitudinal analysis of integrating evidence-based medicine into a medical student curriculum. Fam Med. 2009 Sep;41(8):585-8.

5. Shakoor MT, Ayub S, Ayubs Z. Research : A Pathway Towards a Cood Curriculum Vitae. Int J Med Students. 2013;1(1):46-7.

6. Madan CR, Teitge BD. The Benefits of Undergraduate Research: The Student's Perspective. The Mentor: An Academic Advising Journal. 2013 May: 1-3. 7. Russell SH, Hancock MP, McCullough J. The pipeline. Benefits of undergraduate research experiences. Science. 2007 Apr 27;316(5824):548-9.

8. Burgoyne LN, O'Flynn S, Boylan CB. Undergraduate medical research: the student perspective. Med Educ Online. 2010 Sep 10;15.

9. Costello A, Zumla A. Moving to research partnerships in developing countries. BMJ. 2000 Sep 30;321(7264):827-9.

10. Moloney A. Latin America faces hurdles in health research. Lancet. 2009 Sep 26;374(9695):1053-4.

11. Miron G, Sorensen K. Strengthening educational research in developing countries. Report of a seminar held at the Royal Swedish Academy of Sciences, Stockholm, 12-14 September 1991. International Institute for Educational Planning, Unesco, 1991. Stockholm, Sweden. p. 211.

12. Bonilla-Velez J, Peña-Oscuvilca A, Sahin I, Córdoba-Crueso WS, Fernandez-Zapico ME. The International Journal of Medical Students, a Platform for Medical Student Research Worldwide. Int J Med Students. 2013;1(1):6-7. 13. Lopatto D. Science in solution: The impact of undergraduate research on student learning. Science in Solution: The Impact of Undergraduate Research on Student Learning. Research Corporation for Science Advancement; 2009.

14. Handelsman J, Pfund C, Lauffer SM, Pribbenow CM. Entering mentoring: a seminar to train a new generation of scientists. Ethics in Science and .... Wisconsin Program for Scientific Teaching; 2005.

\section{Acknowledgments}

To my parents, Prof. Hamdy Aly, and my team: Zeinab Hassan, Muayad Alzuabi, Omnia Kadura, Diaa Hussein, Ebtesam El-shennawy, it would be impossible without your support and help.

\section{Conflict of Interest Statement at Funding}

The authors have no funding, financial relationships or conflicts of interest to disclose.

\section{Author Contributions}

Conception and design the work/idea: MAH. Write the manuscript: MAH.

Cite as:

Al-Husseini M. Research as a Student: Is It Worth a Try? An Insightful Experience from a Middle Eastern Student. Int J Med Students. 2014 Mar-Jun;2(2):71-73. 